\title{
Modelling natural forest expansion on a landscape level by multinomial logistic regression
}

\author{
P. CORONA ${ }^{1}$, P. CALVANI ${ }^{1}$, G. S. MUGNOZZA ${ }^{1}$, \& E. POMPEI ${ }^{2}$ \\ ${ }^{1}$ Dipartimento di Scienze dell'Ambiente Forestale e delle sue Risorse, University of Tuscia, Viterbo, Italy and ${ }^{2}$ Corpo Forestale \\ dello Stato, Ministero delle Politiche Agricole e Forestali, Roma, Italy
}

\begin{abstract}
Natural forest expansion is one of the most relevant landscape changes in many temperate countries. Although large areas are involved, relatively few studies have been carried out with the objective of unravelling the specific impact of the individual factors characterising the sites prone to such a process. The aim of this article is to present a research tool for assessing the factors characterising farmland sites prone to natural conversion from crop growing and pasture to forests and other wooded land (OWL), and for predicting the probability of such a land-use change. The methodological approach is based on multinomial logistic regression. As a case study, the approach was applied to land-use classification repeated on the same sites in a large area of central Italy on two successive occasions, spanning two decades, from the beginning of the 1980 s up to 2002. Of all the factors assessed, landscape attributes were identified as a sufficient subset for quantitative prediction of change from farmland to OWL or to forest. The tested modelling approach is explicitly empirical and planning-oriented. From a quantitative point of view, the precision of the models may be only indicative for assessing land-use change probability for single observations, while it is appropriate for predicting mean probabilities at a landscape mapping level, where it is possible to sample a number of sites. At this level, the approach is a useful tool for simulating future landscape scenarios related to natural forest expansion.
\end{abstract}

Keywords: Landscape changes, forest re-colonisation, predictive mapping

\section{Introduction}

In many countries, particularly in the northern hemisphere, forests are increasing due to their natural expansion on abandoned crop and pasture land (FAO 2007). Knowledge about the processes occurring in abandoned farmland is found piecemeal in several studies. The analysis of historical and landuse changes has provided a general pattern of vegetation succession following farming abandonment, where land is re-colonised by spontaneous vegetation, and passes from a herbaceous phase to a shrub-dominated phase, and then to a forested phase (e.g. Gray et al. 1987; Prach et al. 2001; Otto et al. 2006). This process, called old-field succession, has been studied extensively in temperate climates (e.g. Nicholson \& Monk 1974; Bazzaz 1975; Inouye et al. 1987; Benjamin et al. 2005) as well as under Mediterranean conditions (e.g. Tatoni et al. 1994;
Debussche et al. 1996; Bonet 2004; Pugnaire et al. 2006).

The impact of this land cover conversion is quite complex and sometimes far reaching. It is known to be driven by several natural and anthropogenic variables, like altitudinal climate gradient, soil and vegetation characteristics, former land-uses, etc. (Tasser et al. 2007), and it may have a critical (either positive or negative) role for biodiversity and landscape conservation (Mazzoleni et al. 2004; Niemela et al. 2005; Poschlod et al. 2005), depending upon local environmental conditions and social perception.

Although large areas are involved, relatively few studies have been carried out with the objective of disentangling the specific impact of the individual factors characterising the sites prone to natural conversion from crop and pasture land to forests and other wooded land (OWL, sensu FAO 2004)

Correspondence: P. Corona, Dipartimento di Scienze dell'Ambiente Forestale e delle sue Risorse, Università della Tuscia. Via S. Camillo de Lellis s.n.c., Viterbo I-01100, Italy. Tel: +390761 357425. Fax: +390761 357389. Email: piermaria.corona@unitus.it 